\title{
Influence of texture on the recrystallization mechanisms in an AZ31 Mg sheet alloy at dynamic rates
}

\author{
N.V. Dudamell a,*, I. Ulacia ${ }^{\text {b }}$, F. Gálvez ${ }^{c}$, S. Yi ${ }^{\text {d }}$, J. Bohlen ${ }^{\text {d }}$, D. Letzig ${ }^{\text {d }}$, I. Hurtado ${ }^{\text {b }}$, M.T. Pérez-Prado ${ }^{a}$
}

\begin{abstract}
A B S T R A C T
An AZ31 rolled sheet alloy has been tested at dynamic strain rates $\left(\dot{\varepsilon} \sim 10^{3} \mathrm{~s}^{-1}\right)$ at $250^{\circ} \mathrm{C}$ up to various intermediate strains before failure in order to investigate the predominant deformation and restoration mechanisms. In particular, tests have been carried out in compression along the rolling direction (RD), in tension along the RD and in compression along the normal direction (ND). It has been found that dynamic recrystallization (DRX) takes place despite the limited diffusion taking place under the high strain rates investigated. The DRX mechanisms and kinetics depend on the operative deformation mechanisms and thus vary for different loading modes (tension, compression) as well as for different relative orientations between the loading axis and the $c$-axes of the grains. In particular, DRX is enhanced by the operation of (c+a) slip, since cross-slip and climb take place more readily than for other slip systems, and thus the formation of high angle boundaries is easier. DRX is also clearly promoted by twinning.
\end{abstract}

\section{Introduction}

Light magnesium alloys have been widely investigated over the last decade due to their potential to replace heavier metals in transport vehicles [1-3]. The deformation mechanisms predominant in $\mathrm{Mg}$ alloys at low temperatures and low strain rates are now known rather well and have been reviewed in several occasions [4-6].

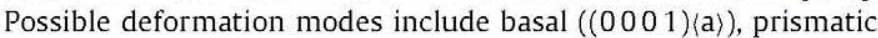
$(\{10-10\}\langle a\rangle)$ and pyramidal $(\{10-11\}\langle a\rangle$ and $\{11-22\}\langle c+a\rangle)$ slip, as well as $\{10-12\}$ extension and $\{10-11\}$ and $\{10-13\}$ contraction twinning. The critical resolved shear stresses (CRSS) of all these deformation modes differ widely at room temperature. A summary of the CRSS obtained from single crystal experiments can be found in [7]. These values are of the order of $5 \mathrm{MPa}$ for basal slip, $10 \mathrm{MPa}$ for extension twinning, 20 MPa for prismatic slip, $40 \mathrm{MPa}$ for pyramidal slip and 70-80 MPa for contraction twinning. Thus, in the highly textured alloys resulting from conventional rolling or extrusion processes the predominant mechanisms will depend strongly on the loading mode (tension or compression) as well as on the loading direction with respect to the c-axes of the polycrystalline aggregate [4-6,8]. In summary, the mechanical behavior and the microstructural evolution during room temperature quasi-static deformation of strongly textured $\mathrm{Mg}$ alloys is highly anisotropic.

With increasing temperature, at low strain rates and in alloys with conventional grain sizes ( $d \sim 5-50 \mu \mathrm{m}$ ), the CRSS of basal slip and extension twinning remain constant, but that of non-basal slip systems and contraction twinning decrease gradually [9]. In particular, at $T>250^{\circ} \mathrm{C}$ the CRSS values of non-basal slip become eventually lower than that of extension twinning. At slightly higher temperatures $\left(\sim T>300^{\circ} \mathrm{C}\right)$ the CRSS for compression twinning also decreases significantly, albeit retaining higher values than the other deformation modes. As a result, with increasing temperature, deformation becomes progressively accommodated by multiple slip $[4,10,11]$. Some authors have also highlighted the important role of grain boundary sliding at $T>300^{\circ} \mathrm{C}[12,13]$. Due to the operation of a larger number of deformation modes, ductility increases and the mechanical behavior of $\mathrm{Mg}$ alloys, even if strongly textured, becomes more isotropic.

High temperature quasi-static deformation of $\mathrm{Mg}$ alloys of conventional grain sizes is usually accompanied by dynamic recrystallization (DRX). Several studies have been carried out to date with the aim of elucidating the predominant DRX mechanisms [6,14-26]. Ion et al. [14] published in 1982 a pioneer study on the subject, in which they reported that DRX was strongly dependent on the deformation temperature. At $T>300-350^{\circ} \mathrm{C}$, discontinuous DRX (DDRX) [27,28], i.e., the nucleation of strain free grains and subsequent growth of these at the expense of deformed regions, 

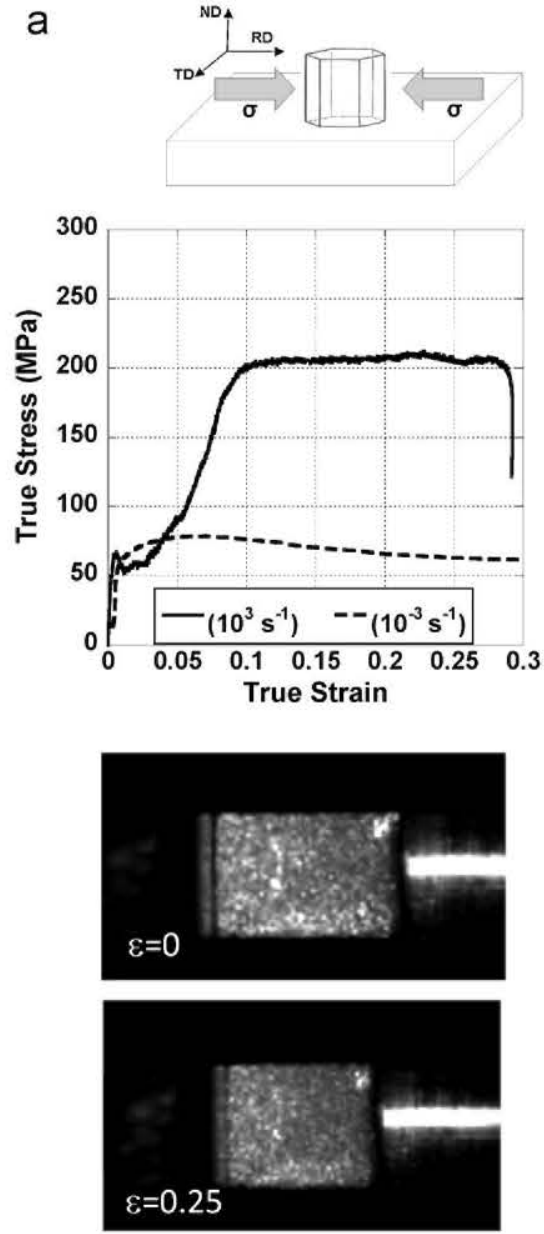
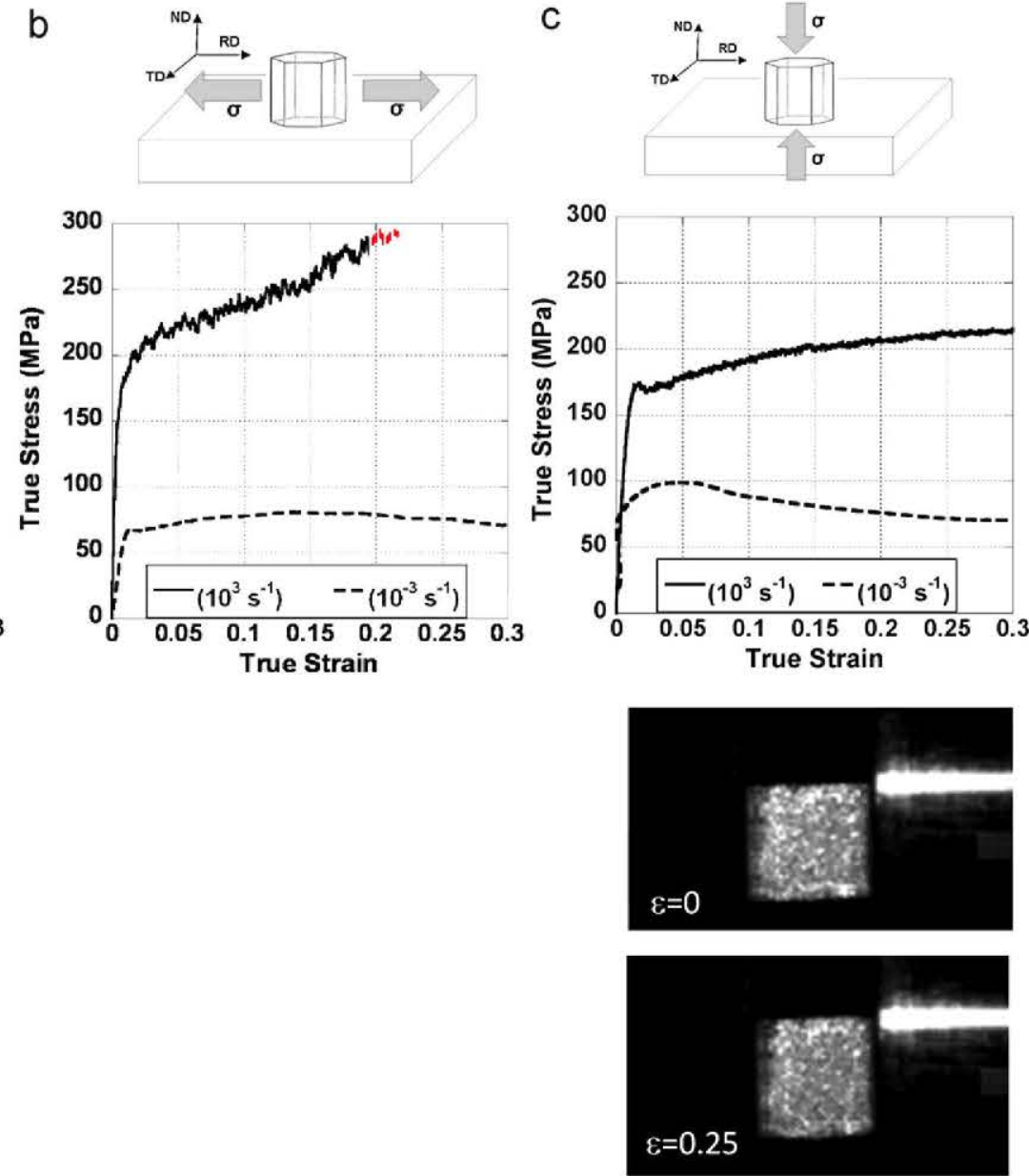

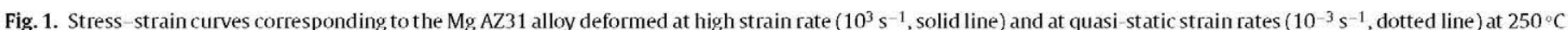

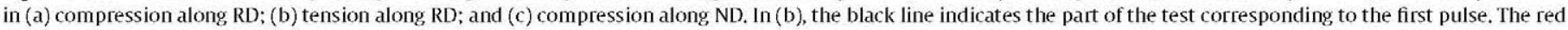

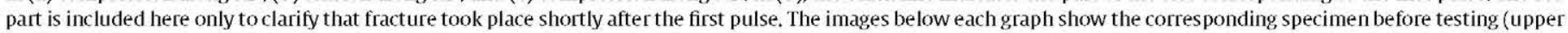

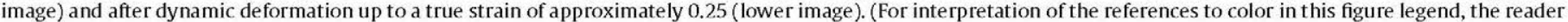
is referred to the web version of the article.)

would predominate. This has been confirmed, for example, in [20]. At lower temperatures, continuous type processes (CDRX), consisting on the formation of subgrain boundaries by dislocation accumulation and the gradual increase of their misorientation $(\theta)$ with strain $[27,28]$, would prevail. Numerous studies have reported the occurrence of continuous processes at moderate temperatures $[6,18,19,21,22,24-26]$. More recently, the specific domains under which DDRX and CDRX predominate, have been associated to critical values of the Zener-Hollomon parameter $(Z)$, as strain rate also plays a significant role (opposite to that of temperature) [29]. Depending on the material composition and microstructural characteristics, DDRX and CDRX may coexist in wide $Z$ ranges.

The high temperature deformation and recrystallization mechanisms of $\mathrm{Mg}$ alloys at impact strain rates $\left(\sim 10^{3} \mathrm{~s}^{-1}\right)$ are currently not well understood, as significantly fewer studies have been carried out in this area [5,30-36]. It is known that the CRSS of nonbasal systems decreases more slowly with temperature than under quasi-static conditions [5] and, thus, twinning is operative even at $T>400^{\circ} \mathrm{C}$ [5,30-33]. Therefore strongly textured $\mathrm{Mg}$ alloys remain mechanically anisotropic at such high temperatures [5]. Dynamically recrystallized grains have been observed in $\mathrm{Mg}$ alloys, such as AZ91 and AZ31, after impact loading at high temperatures [30-32]. However, the DRX mechanisms operative under these extreme conditions are not known.
The aim of the present work is to investigate the DRX mechanisms predominant in a rolled AZ31 sheet alloy at dynamic strain rates as a function of the loading mode and of the relative orientation between the loading axis and the $c$-axes of the polycrystalline aggregate. With that purpose, the evolution of the microstructure, the texture, and the grain boundary distribution with strain is examined when the rolled AZ31 sheet is compressed along the rolling (RD) and normal (ND) directions and tensile tested along the RD. The dynamic deformation and DRX mechanisms will be compared to those prevalent at quasi-static strain rates.

\section{Experimental procedure}

\subsection{Material: initial microstructure}

The material under study is a $\mathrm{Mg}$ alloy $\mathrm{AZ31}(\mathrm{Mg}-3 \% \mathrm{Al}-1 \% \mathrm{Zn})$. Two rolled and annealed sheets, 1 and $3 \mathrm{~mm}$ in thickness, were purchased from Magnesium Elektron. The initial microstructures of the two AZ31 sheets with 1 and $3 \mathrm{~mm}$ thickness are formed by equiaxed grains, with average sizes of 10 and $13 \mu \mathrm{m}$, respectively. Both have a characteristic strong basal texture. In the following we will refer to both sheets as "the AZ31 alloy", as their microstructure and mechanical behavior are basically identical. Further considerations about the similarity of the two materials can be found in [5]. 


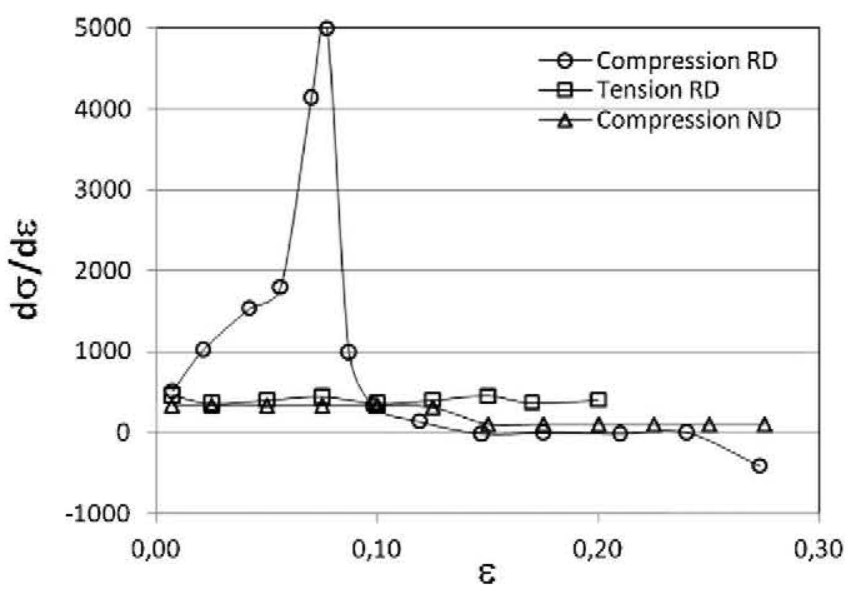

Fig. 2. Work hardening behavior corresponding to the AZ31 sheet alloy deformed at $250^{\circ} \mathrm{C}$ and $10^{3} \mathrm{~s}^{-1}$.

\subsection{Mechanical testing}

High strain rate $\left(\dot{\varepsilon} \sim 10^{3} \mathrm{~s}^{-1}\right)$ tension and compression tests were performed in the AZ31 alloy at $250^{\circ} \mathrm{C}$ up to failure and up to several intermediate strains using a Hopkinson bar furnished with a high speed camera. Samples were heated at $10^{\circ} \mathrm{C} / \mathrm{min}$ and they remained at this temperature during half an hour in order to achieve the temperature stabilization. In the compression tests the specimens were dynamically loaded to a predefined strain level, using a stop-ring technique which limits the displacement of the incident Hopkinson bar. Ring stoppers of specific heights were machined out of an F522 steel. Two nickel superalloy (RENE-41) bars, $1 \mathrm{~m}$ in length and 19 and $10 \mathrm{~mm}$ in diameter, respectively, were machined for this purpose. In the tension tests, momentum trapping fixtures were used in order to interrupt testing and obtain samples deformed at different strains. The incident and transmitted bars in tension tests were made of aluminum AA6061-T6 with $15.87 \mathrm{~mm}$ diameter and $1.44 \mathrm{~min}$ length. Aluminum bars were used in order to minimize the impedance difference between the bars and specimen and also to increase the signal/noise ratio. The maximum loading duration with the current apparatus setup is $200 \mu \mathrm{s}$ as governed by the maximum length of the striker. Compression tests were performed along the RD in $3 \mathrm{~mm} \times 3 \mathrm{~mm} \times 4.5 \mathrm{~mm}$ specimens and along the NDin $3 \mathrm{~mm} \times 3 \mathrm{~mm} \times 3 \mathrm{~mm}$ cubes. Tensile tests along the RD were performed in dog-bone shaped tensile specimens with a gage length of $12.5 \mathrm{~mm}$ and a width of $1.75 \mathrm{~mm}$. After the tests, samples were quickly removed from the machine and put on metallic surface with the purpose of accelerate the cooling of the small samples. In order to reduce friction, solid graphite was used as lubricant. As Hopkinson bar has works in the elastic regime, dynamic stress-strain curves were calculated using the elastic modulus of the bars.

Quasi-static tests at a strain rate of $10^{-3} \mathrm{~s}^{-1}$ were also carried out until failure along the same directions in order to compare the variations in the microstructural evolution with the strain rate. These tests were carried out in a conventional universal testing

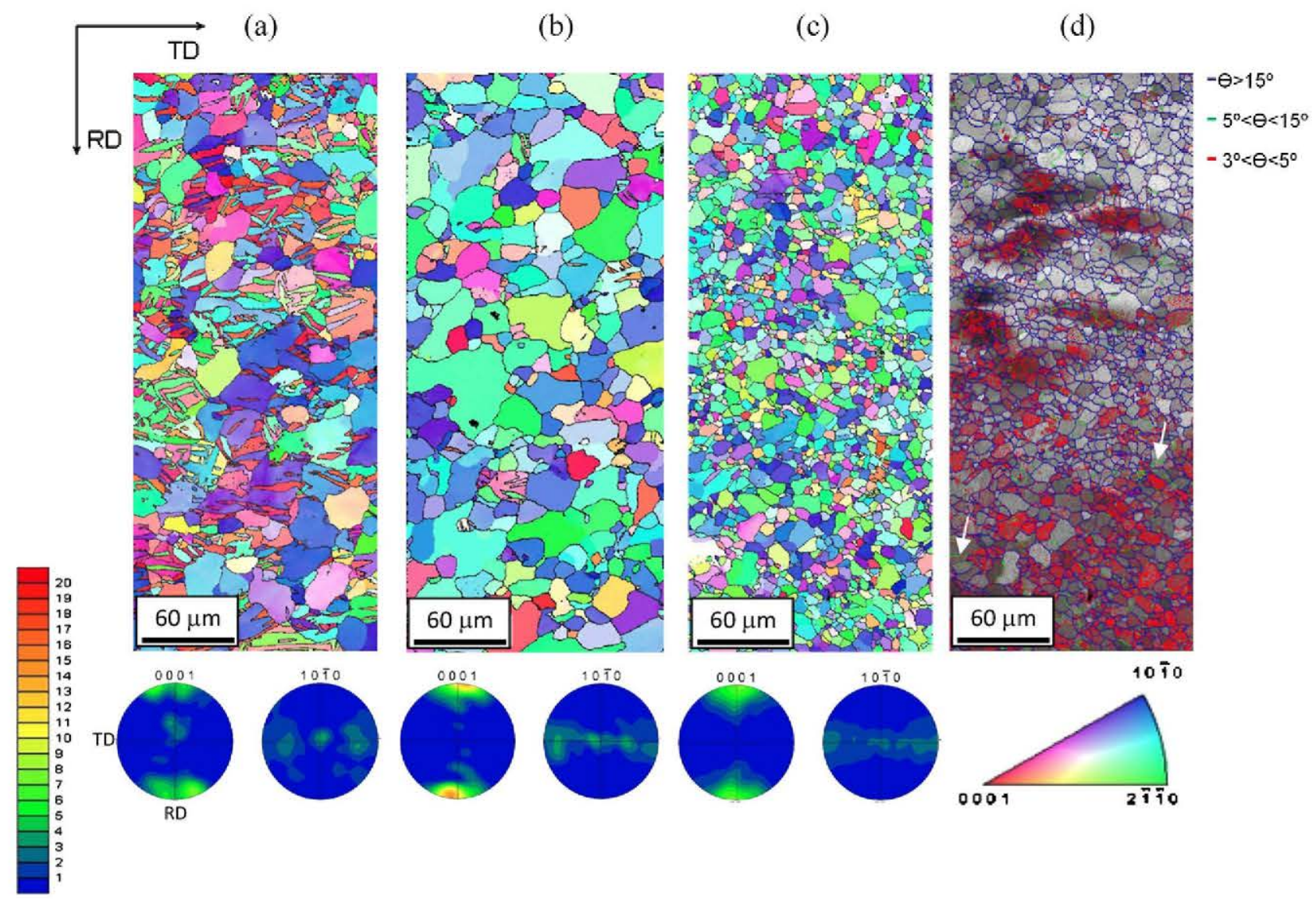

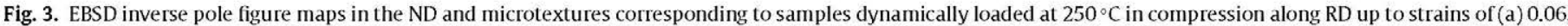

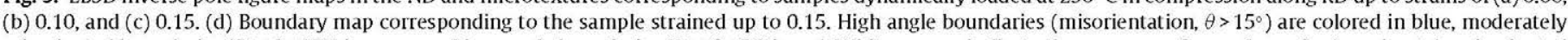

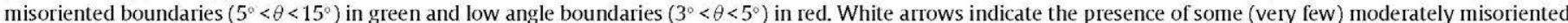

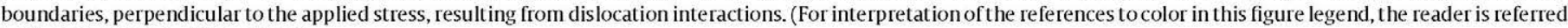
to the web version of the article.) 


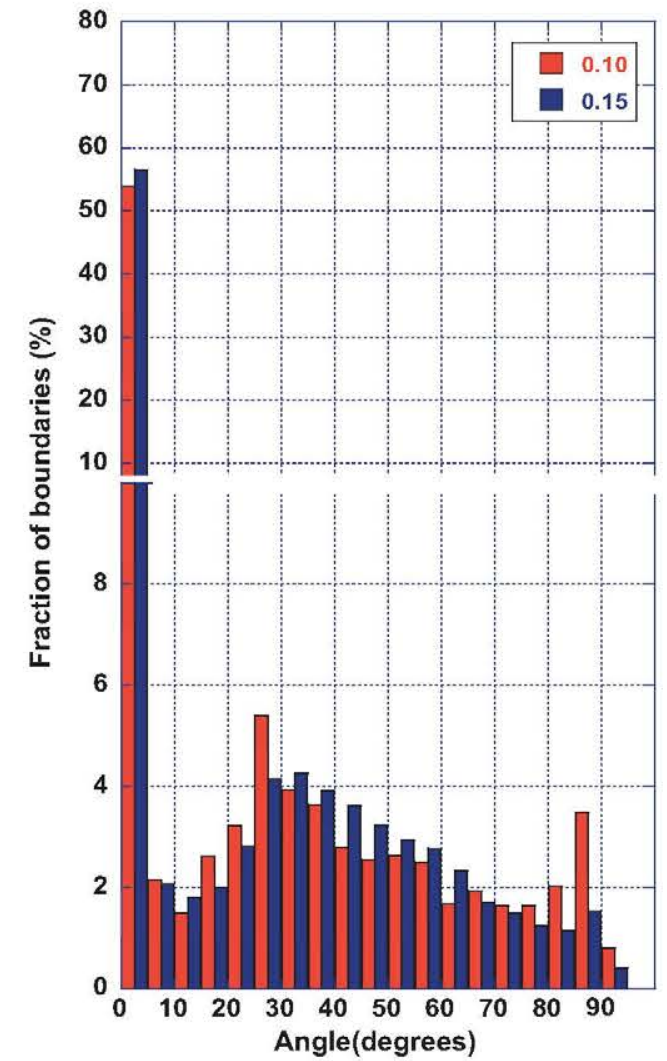

Fig. 4. Misorientation distribution histograms corresponding to the AZ31 sheet alloy compressed along RD at $10^{3} \mathrm{~s}^{-1}$ and $250^{\circ} \mathrm{C}$ up to strains of 0.10 and 0.15 .

machine (Instron) using the same specimen geometries, heating procedure and lubricant described above. To calculate quasi-static stress-strain curves, the stiffness of the Instron machine was taken into account. Tests were found very reproducible as in dynamic as quasi-static tests.

\subsection{Microstructure examination}

The microstructure and the texture of a number of samples compressed along the RD and the ND and tensile tested along the RD at $250^{\circ} \mathrm{C}$ up to various strain levels were analyzed by electron backscatter diffraction (EBSD) using the TSL-OIM ${ }^{\mathrm{TM}}$ software in a Zeiss Ultra $55^{\text {TM }}$ FEG-SEM. Sample preparation for EBSD investigations included grinding with $4000 \mathrm{SiC}$ paper, mechanical polishing with a $0.05 \mu \mathrm{m}$ silica suspension and final electro-chemical polishing for $90 \mathrm{~s}$ at $33 \mathrm{~V}$ using the $\mathrm{AC} 2^{\mathrm{TM}}$ commercial electrolyte. The microstructure is represented by EBSD orientation maps and the texture by pole figures recalculated from the EBSD orientation data. In order to investigate the operative deformation and DRX mechanisms, the nature of the grain boundaries present in all the samples was analyzed from the EBSD data. Additionally, the grain size of various samples was calculated by the linear intercept method in the EBSD orientation maps using only grain boundaries with misorientations higher than $15^{\circ}$. The volume fraction of material oriented as specific texture components was calculated using the EBSD software.

\section{Results}

Fig. 1 illustrates the stress-strain curves corresponding to the AZ31 samples deformed at $250^{\circ} \mathrm{C}$ at dynamic $\left(10^{3} \mathrm{~s}^{-1}\right)$ and at quasistatic $\left(10^{-3} \mathrm{~s}^{-1}\right)$ rates in compression along the RD (Fig. 1a), in tension along the $\mathrm{RD}$ (Fig. $1 \mathrm{~b}$ ) and in compression along the ND
(Fig. 1c). Images of the samples deformed in compression right before testing and after a true strain of 0.25 have been added. At quasi-static strain rates, in all three cases, the stress-strain curves have a "concave-down" shape, indicative of the operation of crystallographic slip. The presence of softening during high temperature deformation of an AZ31 sheet is consistent with the observations of other authors [e.g. 4, 18, 25] and it has been attributed to the occurrence of dynamic recrystallization $[18,25]$. The peak strains are 0.06 in compression along the RD, 0.14 in tension along the RD and 0.05 in compression along the ND. Ductility values exceeding 0.4 (strain at which the compression tests were interrupted) can be obtained in all cases.

At high strain rates the yield and maximum stresses are significantly higher than those measured at quasi-static rates, but the elongation to failure is smaller in all three testing conditions. Fig. 2 illustrates the work hardening rates for the three tests. Significant differences can be found between the three curves. The one corresponding to the compression test along the RD (Fig. 1a) exhibits first a "concave-up" stage, indicative of the presence of twinning, which is known to occur at high temperatures under dynamic conditions [5,30-33]. This is followed by significant strain hardening up to a strain of approximately 0.08 and, subsequently, a stage of practically zero hardening until fracture at a strain of 0.28. The curve corresponding to the tension test along the RD (Fig. 1b) has a "concave-down" shape, characteristic of the predominance of crystallographic slip, and exhibits work hardening until fracture. Finally, the curve corresponding to compression along the ND also has also a "concave-down" shape and the strength increases monotonously with strain. The work hardening rate is positive, but smaller than the one observed in tension along the RD. The ductility values obtained are approximately 0.28 in compression along the $\mathrm{RD}, 0.22$ in tension along the RD and 0.38 in compression along the ND.

Fig. 3 illustrates the evolution of the microstructure and the texture during compression along the RD. EBSD inverse pole figure maps in the ND and the corresponding pole figures are shown for samples deformed up to strains of 0.06 (Fig. 3a), 0.10 (Fig. 3b), and 0.15 (Fig. 3c). A significant amount of extension twinning has indeed taken place at a strain of 0.06. It is well known that extension twins propagate rapidly in AZ31 at low temperatures and quasi-static rates [37]. It is also remarkable that a similar effect can be observed at the current testing conditions, which involve high temperatures and very high strain rates. The volume fraction of twinned material is $72 \%$. This value is slightly lower than that observed for similar strains at low strain rates and room temperature (86\%, [38]), but still very high. Twinning results in a lattice rotation of $86^{\circ}$ around the $\langle 11-20\rangle$ axis, giving rise to a characteristic texture, formed by two maxima parallel to the RD in the $(0001)$ pole figure and to a maximum parallel to the ND in the (10-10) pole figure. The grain size at this strain is $6 \mu \mathrm{m}$. The decrease in grain size with respect to the as-received material is attributed mainly to the presence of a significant amount of twin boundaries. With increasing deformation extension twins propagate even further. At a strain of 0.10 (Fig. 3b) the twinned volume fraction is $93 \%$. Accordingly, the grain size increases to $12 \mu \mathrm{m}$, as twin propagation has now basically encompassed the entire grains and very few twin boundaries remain. It is well known that the twinned regions, in which the compression axis is parallel to the $c$-axes, pyramidal $\langle c+a\rangle$ and basal slip are the predominant deformation mechanisms $[39,40]$. As shown in Figs. 1 and $2 a$, for strains higher than 0.10 , the work hardening rate decreases practically to zero. This is accompanied by a dramatic change in the microstructure. In particular, at a strain of 0.15 (Fig. 3c), the microstructure is formed by equiaxed grains, $6 \mu \mathrm{m}$ in size, and a fiber texture, with the $\langle 0001\rangle$ axis parallel to the RD, develops. These two observations are consistent with the occurrence of dynamic recrystallization. Fig. 4 shows the 
(a)

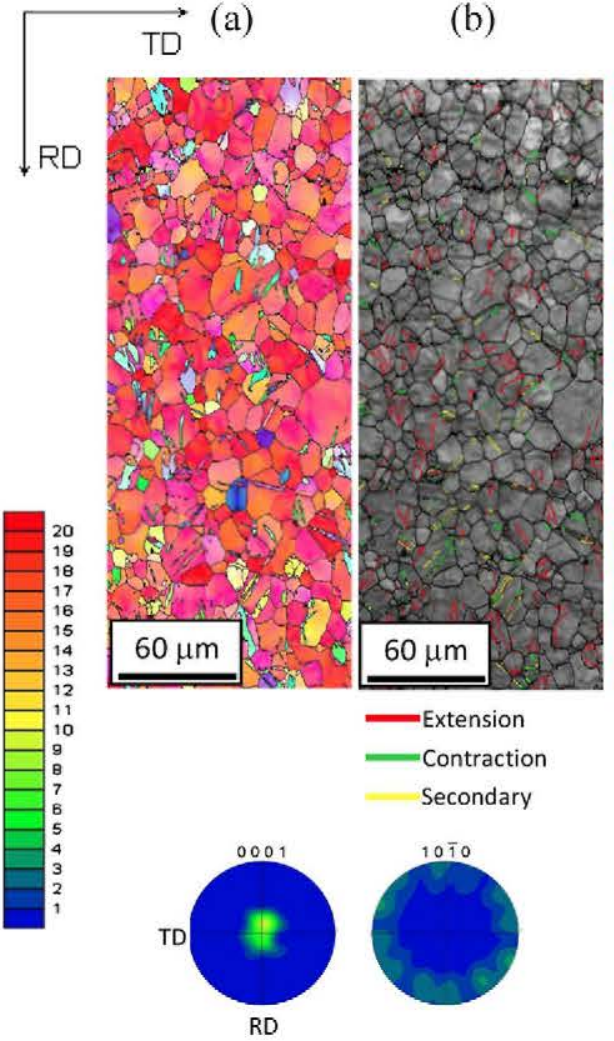

(c)

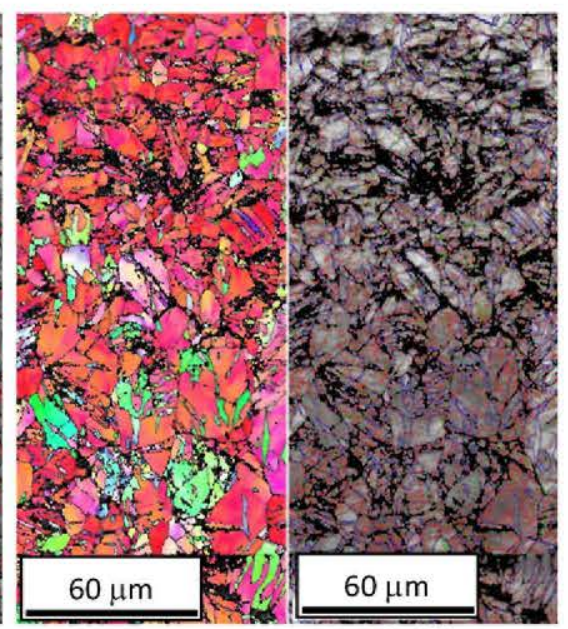

$-\theta>15^{\circ}$

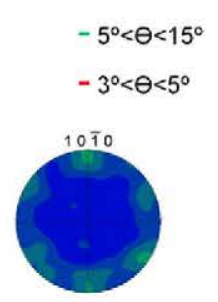

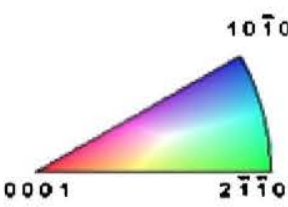

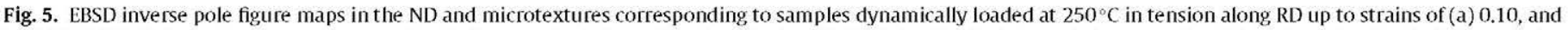

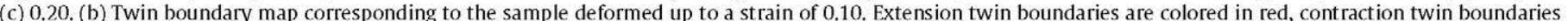

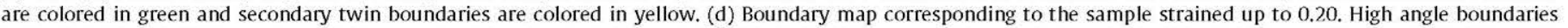

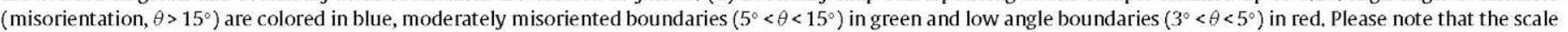

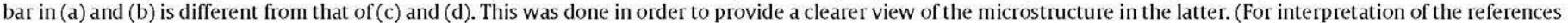
to color in this figure legend, the reader is referred to the web version of the article.)

misorientation distribution histograms corresponding to the samples deformed up to strains of 0.10 and 0.15 . In the latter there is a higher proportion of boundaries with misorientation angles $(\theta)$ ranging from approximately $30^{\circ}$ to $65^{\circ}$ and a lower proportion of boundaries with $\theta$ between $5^{\circ}$ and $30^{\circ}$. It seems the newly created high angle boundaries are not formed by a gradual increase in misorientation as, in that case, a higher proportion of boundaries with $\theta$ between $5^{\circ}$ and $30^{\circ}$ should be present in the recrystallized sample than in the sample deformed up to a strain of 0.10 . This suggests that discontinuous DRX is the main recrystallization mechanism. Nevertheless, the presence of some (very few) moderately misoriented boundaries (with $\theta$ between $5^{\circ}$ and $15^{\circ}$ ), lying perpendicular to the applied stress and thus subdividing the original grains, resulting from dislocation interactions, could also be detected. Two of these boundaries are pointed by white arrows in Fig. 3d.

Fig. 5 illustrates the microstructure and the texture of the sample deformed in tension along the RD up to strains of 0.10 (Fig. $5 \mathrm{a}$ and b) and 0.20 (Fig. $5 \mathrm{c}$ and d). After a strain of 0.10 the grains remain fairly equiaxed and the average size is $8 \mu \mathrm{m}$. Extension, contraction and secondary twinning are apparent to a small extent (Fig. 5b) and thus twin boundaries contribute to the grain refinement. A deformation texture, in which basal planes are parallel to the rolling plane and $\langle 10-10\rangle$ directions are parallel to the loading axis (RD), becomes progressively better defined with increasing deformation. This reveals that the main deformation mechanism is prismatic slip, together with basal slip $[4,5,40,41]$. At the largest strain level investigated ( 0.20 , Fig. $5 \mathrm{c}$ and d) a new maximum appears at the edge of the $(0001)$ pole figure, denoting the presence of a larger volume fraction of tensile twins with increasing deformation. This is quite remarkable, as tensile twinning is not a favorable mechanism when testing along the RD. Furthermore, at this high strain, the grain size distribution is bimodal: fine recrystallized grains, approximately $2 \mu \mathrm{m}$ in size, are embedded in a matrix of larger grains of about $8 \mu \mathrm{m}$ in diameter. Recrystallized grains are mostly located inside twins or along grain boundaries. Inspection of the boundary map of $5 \mathrm{~d}$ reveals, additionally, the formation of low to moderately misoriented boundaries within grains, due to dislocation interactions. Together, the stabilization of a deformation texture and the appearance of recrystallized grains mostly near twin or regular grain boundaries, suggest that the DRX mechanism predominant during tensile deformation of the AZ31 alloy along the RD is of a continuous nature, predominantly rotational DRX.

Fig. 6 depicts the microstructure and microtexture evolution corresponding to the sample deformed in compression along the ND up to strains of 0.07 (Fig. 6a), 0.095 (Fig. 6b) and 0.17 (Fig. 6c

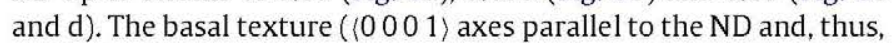
to the loading axis) remains basically unchanged with increasing deformation. The values of the average grain sizes for the three strains investigated are $12 \mu \mathrm{m}, 10 \mu \mathrm{m}$, and $11 \mu \mathrm{m}$, respectively. All these values are lower than the original grain size $(13 \mu \mathrm{m})$. Since the planes where the EBSD measurements in Fig. 6 were taken are perpendicular to the compression axis, it is expected that, for pure geometrical reasons, in the absence of any recrystallization process, the average grain size along this plane should have increased with deformation. Specifically, it is estimated that the grain size should increase to $\sim 14 \mu \mathrm{m}$ after a strain of 0.17 . Thus, the measured grain size decrease is a sign of the occurrence of DRX. The predominating DRX mechanisms can be evaluated by comparing in Fig. 7 the misorientation distribution histograms of the samples deformed up to 
(a)
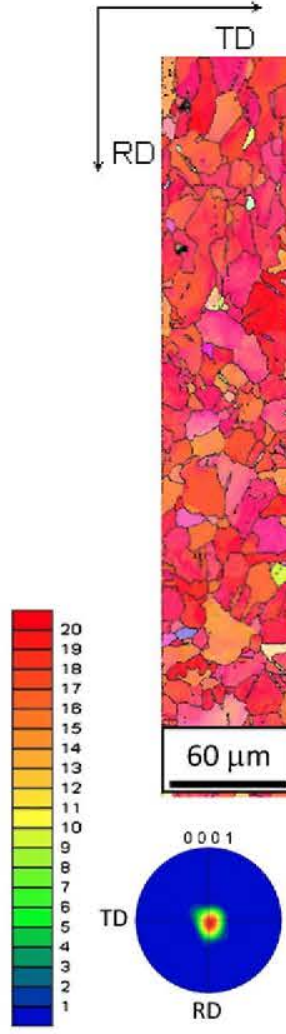

(b)

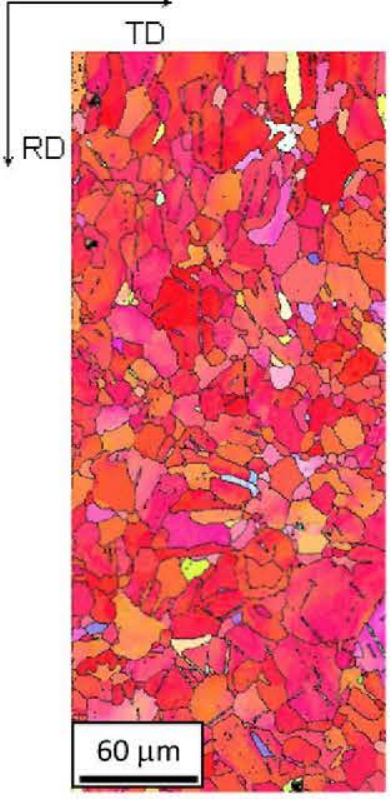

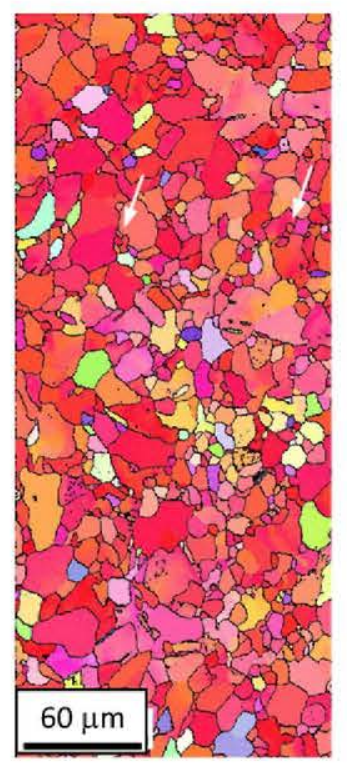
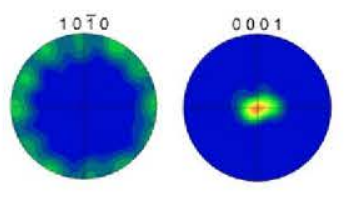

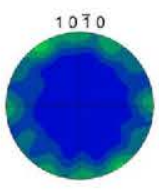

(c)

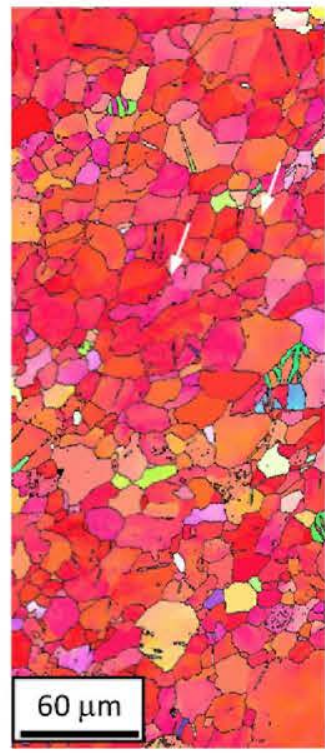

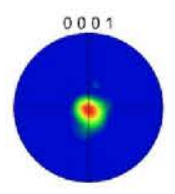

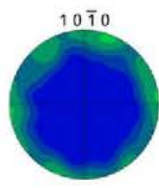

(d)
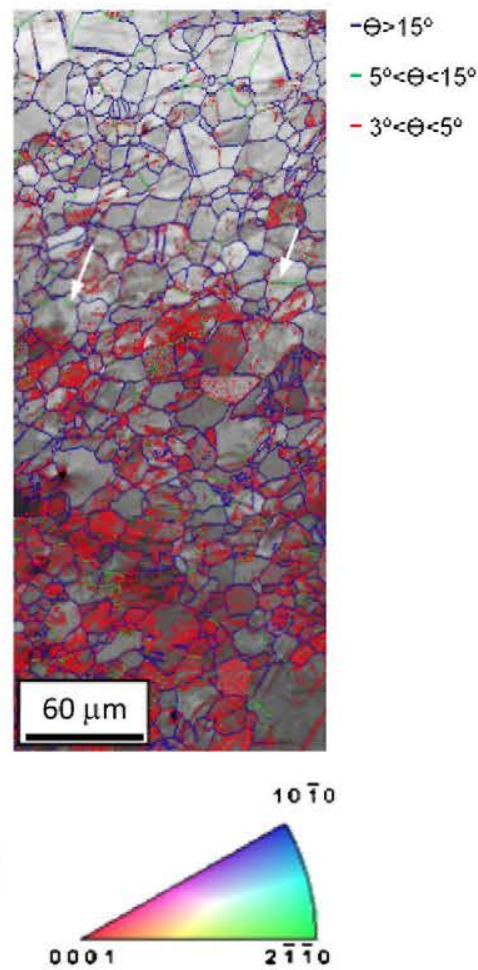

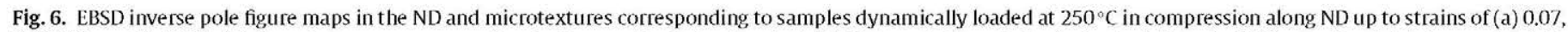

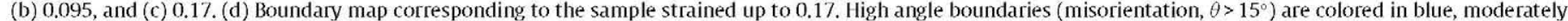

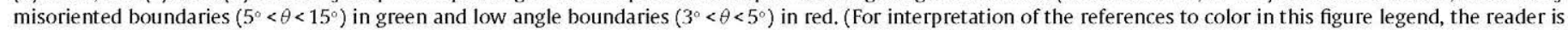
referred to the web version of the article.)

a strain of 0.095 and 0.17 . The latter has a smaller fraction of boundaries with misorientations between $3^{\circ}$ and $5^{\circ}$, but the fraction of boundaries in all the remaining misorientation ranges up to $60^{\circ}$ is higher. This suggests that a combination of discontinuous DRX, which would justify the increase of high angle boundaries with $\theta>15^{\circ}-20^{\circ}$, and grain subdivision by continuous DRX, which would explain increase in boundaries between $5^{\circ}$ and $\sim 15^{\circ}-20^{\circ}$ [42], is taking place. Some of the newly formed moderately misoriented boundaries have been highlighted in Fig. $6 \mathrm{~d}$ with white arrows. A closer inspection of Fig. $6 \mathrm{~b}-\mathrm{d}$ reveals that a significant fraction of the original high angle boundaries become wavy as a consequence of local lattice rotations in those areas. In this figures it is also possible to notice small, recrystallized grains, completely surrounded by high angle boundaries, most likely resulting from a DDRX-type process. They have been pointed out using white arrows.

Altogether, the results described above suggest that the DRX predominating during uniaxial high strain rate deformation of the $\mathrm{MgAZ31}$ alloy at $250^{\circ} \mathrm{C}$ depend on the relative orientation between the loading axis and the crystalline $c$-axes and, in turn, on the predominant deformation mechanisms. In particular, when twinning followed by pyramidal and basal slip are dominant (compression along the RD), recrystallization, mainly by DDRX, takes place readily, leading to a stage of zero hardening. When, on the contrary, prismatic and basal slip are active (tension along the RD), the material exhibits a high resistance to recrystallization and strong hardening. Finally, when pyramidal and basal slip are operative (compression along the ND), DDRX also takes place, in conjunction with CDRX. These differences can be also clearly observed by examining the KAM maps corresponding to samples deformed up to similar strains in compression along the RD (Fig. 8a), in tension along the RD (Fig. 8b), and in compression along the ND (Fig. 8c). It can be clearly noticed that, in the tension test, the dislocation density within grains is significantly higher than in the compression tests, which recrystallize more readily. The map of Fig. $8 \mathrm{~b}$ provides further proof that the DRX mechanism during tension along the RD up to the measured strain is of a continuous nature, as the intragranular misorientation in the small, recrystallized grains that develop during deformation is also high. (And it should be significantly lower if these grains would have formed by DDRX).

\section{Discussion}

The results presented above reveal that there is a higher resistance to DRX when testing dynamically in tension along the RD than during compression along the RD and along the ND. These observations can be rationalized as follows.

The influence of texture on DRX at quasi-static rates has been analyzed in a few earlier studies. In a pioneering work on the subject, Kaibyshev et al. [16] reported that the kinetics of DRX in an hot-pressed MA14 Mg rod (Mg-Zn-Zr), with a typical prismatic fiber texture and deformed in compression at $300^{\circ} \mathrm{C}$ and $2.8 \times 10^{-3} \mathrm{~s}^{-1}$, were dependent on the crystallographic texture. In particular, they observed that if the compression axis was parallel or perpendicular to the basal planes, DRX took place readily and an almost fully recrystallized structure was obtained at moderate strains. However, when the compression axis was tilted $45^{\circ}$ with respect to the basal planes, DRX took place more slowly. In the former, the reported operative slip systems at the strain at which recrystallization started are prismatic, pyramidal $\langle a\rangle$ and 


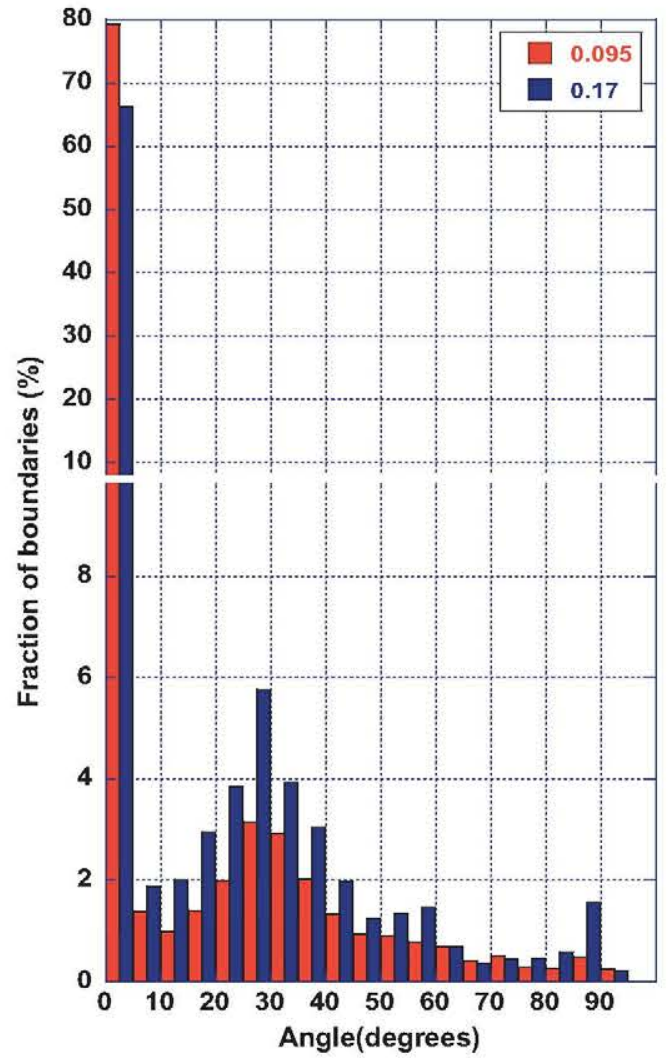

Fig. 7. Misorientation distribution histograms corresponding to the AZ31 sheet alloy compressed along ND at $10^{3} \mathrm{~s}^{-1}$ and $250^{\circ} \mathrm{C}$ up to strains of 0.095 and 0.17 . basal. In the latter, only basal and prismatic slip are found to be active. Thus, Kaibyshev et al. [16] concluded that the kinetics of DRX were accelerated when all three main slip modes (basal, prismatic and pyramidal $\langle\mathrm{a}\rangle$ ) are active. This, reportedly, is due to the fact that the operation of many slip modes favors the cross-slip of basal dislocations into non-basal planes. These non-basal dislocations have high stacking fault energies (SFE $\mathrm{basal}<50 \mathrm{~mJ} \mathrm{~m}^{-2}$; $\left.\mathrm{SFE}_{\text {prismatic }}=354 \mathrm{~mJ} \mathrm{~m}^{-2} ; \mathrm{SFE}_{\text {pyramidal }}=452 \mathrm{~mJ} \mathrm{~m}^{-2}[43,44]\right)$ and, thus, can easily climb and arrange into new boundaries by the Friedel-Escaig mechanism. Del Valle et al. [19] also observed an enhancement of DRX in AZ31 samples oriented for multiple slip versus others initially oriented only for single (basal) slip. Finally, Barnett [29] reported a delay in DRX in an AZ31 sheet deformed in plane strain under conditions in which prismatic slip would predominate versus others in which $\langle c+a\rangle$ and basal slip are operative.

Our results at dynamic rates are consistent with the above observations at quasi-static rates and also support the fact that the kinetics of DRX is related to the operative deformation mechanisms. In particular, we observe a higher resistance to recrystallization when prismatic slip and basal slip operate (tension along the RD) than when a combination of $\langle c+a\rangle$ and basal slip are active (compression along the ND). This can be understood taking into account that pyramidal slip has more independent systems (5) than prismatic slip (2), and that the SFE of pyramidal dislocations is also significantly higher. Together, these two factors favor the occurrence of cross-slip and climb when pyramidal slip is active. We have also observed that the most favorable conditions for DRX at high strain rates are reached during compression along the RD, when extensive tensile twinning is followed by a combination of basal and pyramidal $\langle c+a\rangle$ slip. Under these conditions DRX takes place homogeneously throughout the microstructure, the final grain size is smaller and the strain hardening is lower than when compressing (a)

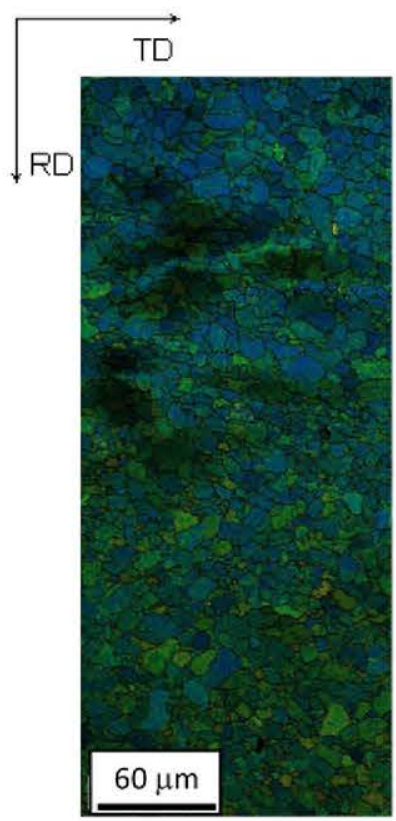

(b)

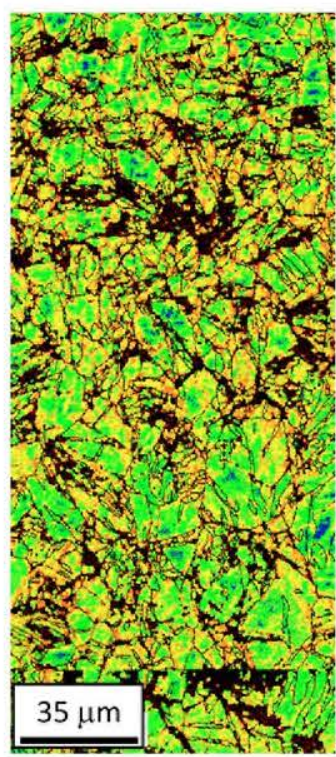

(c)
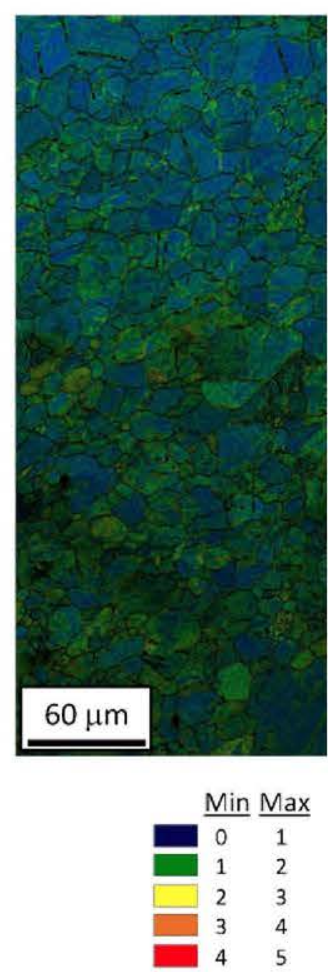

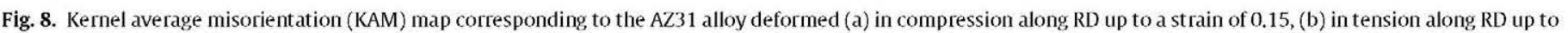
a strain of 0.20 and $(\mathrm{c})$ in compression along ND up to a strain of 0.17 . 
along the ND, where only basal and pyramidal $\langle c+a\rangle$ slip operate from the first stages of deformation. Thus, our results suggest that the operation of twinning during high temperature deformation at dynamic rates in the AZ31 alloy enhances DRX. The beneficial effect of twinning on DRX in Mg alloys as has been observed previously under quasi-static conditions [e.g. 45-49] and it has been attributed to the large stresses accumulated close to twin boundaries, which promote the operation of multiple slip modes.

Fig. 1 reveals that DRX takes place more easily at quasi-static than at dynamic strain rates, resulting in a much more pronounced softening. This may be explained by the easiness of diffusion at low strain rates, as well as by the more pronounced decrease of the CRSS of $\langle c+a\rangle$ slip with temperature under such conditions [5]. Thus, for example, at $250^{\circ} \mathrm{C}$ and $10^{-3} \mathrm{~s}^{-1}$, it is expected that prismatic, $\langle\mathrm{C}+\mathrm{a}\rangle$ and basal slip operate, giving rise to the onset of recrystallization. However, at that same temperature and dynamic rates, the CRSS of pyramidal slip is still significantly higher than that of prismatic slip, and therefore only the latter and basal slip are active, resulting in a strong resistance to DRX, as is observed in the current study.

\section{Conclusions}

The recrystallization mechanisms operative during dynamic deformation of an AZ31 sheet alloy at $250^{\circ} \mathrm{C}$ have been investigated as a function of the loading mode and the crystallographic texture. The as-received rolled and annealed sheet, with a typical strong basal texture, has been tested at $10^{3} \mathrm{~s}^{-1}$ in compression along the $\mathrm{RD}$, in tension along the RD and in compression along the ND. The following conclusions have been drawn from the present study:

1. The DRX mechanisms and kinetics depend on the operative deformation mechanisms and thus vary for different loading modes (tension, compression) as well as for different relative orientations between the loading axis and the $c$-axes of the grains.

2. The highest resistance to dynamic recrystallization was found when the material was tested in tension along the RD. In this case, in which both prismatic and basal slip operate, the work hardening rate was higher than in the compression tests. Some recrystallized grains do appear at the latest stages of deformation $(\varepsilon \sim 0.20)$ as a result of rotational dynamic recrystallization (RDRX). DRX took place more readily under compression along the RD, when twinning, $\langle c+a\rangle$ and basal slip operate. Recrystallization results in a stage of zero hardening rate. The main recrystallization mechanism is DDRX.

3. DRX at dynamic rates is enhanced by the operation of $\langle c+a\rangle$ slip, as the existence of a large number of independent systems and the high stacking fault energy of pyramidal dislocations favor cross-slip and climb and, thus, the formation of new high angle boundaries. DRX is also promoted by twinning.

\section{Acknowledgements}

The authors would like to thank the vehicle interior manufacturer, Grupo Antolin Ingeniería, S.A., within the framework of the project MAGNO2008-1028-CENIT funded by the Spanish Ministry of Science and Innovation. Funding from the Basque Government through the Manufacturing 0,0 project (within the Etortek
Programme) is acknowledged. Assistance from María Jesús Pérez (UPM, Madrid) and Jesús Reales (CENIM, Madrid) with the mechanical testing and from Yu Kyung Shin and V. Kree (HZG, Germany) with the EBSD analysis was appreciated.

\section{References}

[1] M. Easton, A. Beer, M. Barnett, C. Davies, G. Dunlop, Y. Durandet, S. Blacket, T. Hilditch, P. Beggs, JOM 60 (2008) 57.

[2] B.L. Mordike, T. Ebert, Mater. Sci. Eng. 302 (2001) 37.

[3] M. Bamberger, G. Dehm, Annu. Rev. Mater. Res. 38 (2008) 505

4] S.R. Agnew, Ö. Duygulu, Int. J. Plasticity 21 (2005) 1161.

[5] I. Ulacia, N.V. Dudamell, F. Gálvez, S. Yi, M.T. Pérez-Prado, I. Hurtado, Acta Mater. 58 (2010) 2988 .

[6] T. Al-Samman, X. Li, S.G. Chowdury, Mater. Sci. Eng. A 527 (2010) 3450.

[7] A. Chapuis, J.H. Driver, Acta Mater. 59 (2011) 1986.

[8] S.B. Yi, J. Bohlen, F. Heinemann, D. Letzig, Acta Mater. 58 (2010) 592.

[9] M.R. Barnett, Metall. Mater. Trans. 34 (2003) 1799.

[10] N. Stanford, K. Sotoudeh, P.S. Bate, Acta Mater. 59 (2011) 4866.

[11] A.S. Khan, A. Pandey, T. Gnäupel-Herold, R.K. Mishra, Int. J. Plasticity 27 (2011) 688 .

[12] B. Hutchinson, M.R. Barnett, A. Ghaderi, P. Cizek, I. Sabirov, Int. J. Mater. Res. 100 (2009) 556

[13] J.A. Del Valle, O.A. Ruano, Acta Mater. 55 (2007) 455

[14] S.E. Ion, F.J. Humphreys, S.H. White, Acta Metall. 30 (1982) 1909

[15] R.O. Kaibyshev, A.M. Galiyev, B.K. Sokolov, Phys. Met. Metallogr. 78 (1994) 209.

[16] R.O. Kaibyshev, B.K. Sokolov, A.M. Galiyev, Texture. Microstruct. 32 (1999) 47.

[17] M.M. Myshlyaev, H.J. McQueen, A. Mwembela, E. Konopleva, Mater. Sci. Eng. A 337 (2002) 121

[18] J.C. Tan, M.J. Tan, Mater. Sci. Eng. A 339 (2003) 124.

[19] J.A. Del Valle, M.T. Pérez-Prado, O.A. Ruano, Mater. Sci. Eng. A 355 (2003) 68.

[20] M.R. Barnett, A.G. Beer, D. Atwell, A. Oudin, Scr. Mater. 51 (2004) 19.

[21] S.B. Yi, S. Zaefferer, H.G. Brokmeier, Mater. Sci. Eng. A 424 (2006) 275.

[22] T. Al-Samman, G. Gottstein, Mater. Sci. Eng. A 490 (2008) 411.

[23] J.A. Del Valle, O.A. Ruano, Mater. Sci. Eng. A 487 (2008) 473.

[24] E. Martin, J.J. Jonas, Acta Mater. 58 (2010) 4253.

[25] D.K. Sun, C.P. Chang, P.W. Kao, Mater. Sci. Eng. A 527 (2010) 7050.

[26] Z. Liu, S. Bai, S. Kang, Scr. Mater. 60 (2009) 403.

[27] R.D. Doherty, D.A. Hughes, F.J. Humphreys, J.J. Jonas, D. Juul Jensen, M.E. Kassner, W.E. King, T.R. McNelley, H.J. McQueen, A.D. Rollett, Mater. Sci. Eng. A 238 (1997) 219.

[28] F.J. Humphreys, M. Hatherly, Recrystallization and Related Annealing Phenomena, Pergamon, 1995

[29] M.R. Barnett, J. Light Met. 1 (2001) 11.

[30] K. Ishikawa, H. Watanabe, T. Mukai, Mater. Lett. 59 (2005) 1511.

[31] K. Ishikawa, H. Watanabe, T. Mukai, J. Mater. Sci. 40 (2005) 1577.

[32] H. Watanabe, K. Ishikawa, Mater. Sci. Eng. 523 (2009) 304

[33] I. Ulacia, C.P. Salisbury, I. Hurtado, M.J. Worswick, J. Mater. Proc. Technol, 211 (2011) 830 .

[34] E. El-Magd, M. Abouridouane, J. Phys. IV France 110 (2003) 15.

[35] L.E. Murr, C. Pizaña, Metall. Trans. A 38 (2007) 2611.

[36] D.L. Zou, L. Zhen, Y.Zhu, C.Y. Xu, W.Z.Shao, B.J. Pang, Mater. Sci. Eng. 527 (2010) 3323.

[37] M. Knezevic, A. Levinson, R. Harris, R.K. Mishra, R.D. Doherty, S.R. Kalidindi, Acta Mater. 58 (2010) 6230.

[38] N.V. Dudamell, I. Ulacia, F. Gálvez, S.B. Yi, J. Bohlen, D. Letzig, I. Hurtado, M.T. Pérez-Prado, Acta Mater. 59 (2011) 6949.

[39] A. Fernández, M.T. Pérez-Prado, Y. Wei, A. Jérusalem, Int. J. Plasticity 27 (2011) 1739.

[40] H. Wang, B. Raeisinia, P.D. Wu, S.R. Agnew, C.N. Tome, Int. J. Sol. Struct. 47 (2010) 2905

[41] Y.B. Chun, C.H.J. Davies, Mater. Sci. Eng. 528 (2011) 3489.

[42] M. Cabibbo, W. Blum, E. Evangelista, M.E. Kassner, M.A. Meyers, Metall. Trans. 39 (2008) 181.

[43] L. Wen, P. Chen, Z.F. Tong, B.Y. Tang, L.M. Peng, W.J. Ding, Eur. Phys. J. B 72 (2009) 397.

[44] A.E. Smith, Surf. Sci. 601 (2007) 5762.

[45] S.B. Yi, I. Schestakow, S. Zaefferer, Mater. Sci. Eng. 516 (2009) 58

[46] S.Q. Zhu, H.G. Yan, J.H. Chen, Y.Z. Wu, J.Z. Liu, J. Tian, Scr. Mater. 63 (2010) 985.

[47] O. Sitdikov, R. Kaibyshev, T. Sakai, Mater. Sci. Forum 419/422 (2003) 521-526.

[48] O. Sitdikov, R. Kaibyshev, Mater. Trans. 42 (2001) 1928.

[49] A. Galiyev, R. Kaibyshev, G. Gottstein, Acta Mater. 49 (2001) 1199. 